\title{
A Landscape-Level Assessment of Whitebark Pine Regeneration in the Rocky Mountains, USA
}

\author{
Sara A. Goeking ${ }^{\circ}$, Deborah K. Izlar, and Thomas C. Edwards
}

Whitebark pine (Pinus albicaulis Engelm.) has recently experienced high mortality due to multiple stressors, and future population viability may rely on natural regeneration. We assessed whitebark pine seedling densities throughout the US Rocky Mountains and identified stand, site, and climatic variables related to seedling presence based on data from 1,217 USDA Forest Service Forest Inventory and Analysis plots. Although mean densities were highest in the whitebark pine forest type, 83\% of sites with seedlings present occurred in non-whitebark pine forest types, and the highest densities occurred in the lodgepole pine forest type. To identify factors related to whitebark pine seedling presence, we compared the results generated from three statistical models: logistic regression, classification tree, and random forests. All three models identified cover of grouse whortleberry (Vaccinium scoparium Leiberg ex Coville) as an important predictor, two models distinguished live and dead whitebark pine basal area and elevation, and one model recognized seasonal temperature. None of the models identified forest type as an important predictor. Understanding these factors may help managers identify areas where natural regeneration of whitebark pine is likely to occur, including sites in non-whitebark pine forest types.

Keywords: Pinus albicaulis, seedlings, recruitment, five-needle pines, forest inventory

W hitebark pine (Pinus albicaulis Engelm.) has experienced high mortality in recent years due to interacting stressors including heat, drought, white pine blister rust (Cronartium ribicola), mountain pine beetle (Dendroctonus ponderosae Hopkins), and absence of fire (Keane and Arno 1993, Raffa et al. 2008, Smith et al. 2008, Keane et al. 2012). As of 2016, the western United States contained an estimated nearly 292 million live and 308 million standing dead whitebark pine trees (Goeking and Izlar 2018); thus, approximately $51 \%$ of all standing whitebark pine trees were dead. This catastrophic mortality raises concerns that cone production in surviving trees will be insufficient to maintain species viability (Leirfallom et al. 2015), thus endangering associated ecosystem services such as snowpack retention (Hutchins and Lanner 1982, Keane et al. 2012, Tomback et al. 2016) and the numerous wildlife species that depend on whitebark pine (U.S. Fish and Wildlife Service 2011).

This high mortality raises the question: can regeneration of whitebark pine across broad scales ensure the viability of the species? Regeneration can occur either via planting of nursery stock or via natural regeneration (Schoettle and Sniezko 2007, Keane et al.
2012, Hansen et al. 2016). One strategy for managing and restoring whitebark pine ecosystems is selection and planting of seeds and seedlings that appear to be resistant to the fatal disease white pine blister rust (Schoettle and Sniezko 2007, Keane and Parsons 2010, Keane et al. 2012, Lonergan et al. 2014), which is ubiquitous across the range of whitebark pine and causes mortality of the majority of infected trees (Smith et al. 2008). This strategy is typically implemented by selecting individual whitebark pine trees that have been exposed to white pine blister rust but have survived or escaped infection and then by collecting cones and propagating seedlings for future outplanting (McKinney and Tomback 2007). However, the process of identifying partially rust-resistant trees, propagating seedlings, and planting can be expensive and logistically difficult across broad scales. Further, this strategy is not guaranteed to be successful because it does not ensure complete genetic resistance to white pine blister rust in progeny (McKinney and Tomback 2007). Therefore, natural regeneration and survivorship of seedlings, saplings, and mature trees may determine future population viability (Schoettle and Sniezko 2007, McCaughey et al. 2009, Larson and Kipfmueller 2010, Keane et al. 2012, Hansen et al. 2016).

Manuscript received June 9, 2017; accepted June 19, 2018; published online August 29, 2018.

Affiliations: Sara A. Goeking (sgoeking@fs.fed.us), USDA Forest Service, Rocky Mountain Research Station, 507 25th Street, Ogden, UT 84401. Deborah K. Izlar (dizlar@fs.fed.us), USDA Forest Service, Pacific Northwest Research Station, P.O. Box 7443, Missoula, MT 59807. Thomas C. Edwards (t.edwards@usu.edu), USGS Utah Cooperative Fish and Wildlife Research Unit, Department of Wildland Resources, Utah State University, Logan, UT 84322.

Acknowledgments: The authors extend sincere gratitude to the multitudes of FIA crews who collected field data. Mary Frances Mahalovich graciously provided spatial data on whitebark pine phylogenetic seed zones as well as helpful comments on results. We are grateful to the associate editor and three anonymous reviewers, whose comments led to substantial improvements of this paper, and to Marcella A. Windmuller-Campione, R. Justin DeRose, Sarah Flannery, Robert E. Keane, and Kristin A. Pelz for reviewing earlier versions of this manuscript. 
Understanding the factors related to natural regeneration of whitebark pine may help managers focus limited resources on appropriate management to maintain or restore this keystone species. Because whitebark pine seed dispersal occurs primarily via caching by Clark's nutcracker (Nucifraga columbiana) (Hutchins and Lanner 1982), whitebark pine often establishes in clusters (Tomback et al. 1993). Germination is typically episodic and may occur several years after disturbances such as wildfire (Tomback et al. 1993, Leirfallom et al. 2015, Perkins 2015). Seedling density and survival have been positively correlated with above-average precipitation and presence of the shrub Vaccinium scoparium Leiberg ex Coville (Tomback et al. 1993) and negatively related to solar radiation and recent fire-caused mortality of whitebark pines (Lierfallom et al. 2015). Larson and Kipfmueller (2010) assessed regeneration across a wide range of environments, including stands attacked by mountain pine beetle, and found that regeneration was unrelated to stand age but positively related to elevation, precipitation, and recent beetle-caused mortality and negatively related to temperature and dominance of subalpine fir (Abies lasiocarpa (Hook.) Nutt.). The combination of negative temperature effects and positive elevation and precipitation effects (Larson and Kipfmueller 2010) suggests that seedling density is largely controlled by climate-related factors. Most of these previous studies of natural whitebark pine regeneration have constrained their study domains to stands dominated by whitebark pine, formerly dominated by whitebark pine prior to recent mortality, or adjacent to whitebark pine-dominated stands (e.g., Larson and Kipfmueller 2010, Lierfallom et al. 2015). Such studies collectively provide insights into natural whitebark pine regeneration patterns, yet landscape-level information about seedling densities in all forest types where whitebark pine occurs is limited.

The objectives of this study were: (1) to assess whitebark pine seedling densities throughout the species' range in the US Rocky Mountains and thus determine where managers trying to enhance natural regeneration of whitebark pine should target their efforts, and (2) to identify stand, site, and climatic variables that are related to the presence of whitebark pine seedlings. To address our first objective, we used data collected from a probabilistic sample to assess seedling densities across all forest types, land cover classes, and ownership classes. We expected that whitebark pine seedling densities would be greatest in stands dominated by whitebark pine, rather than in forest types dominated by other species, based on the previously observed negative relationship of whitebark pine seedling density to subalpine fir dominance (Larson and Kipfmueller 2010) and because Clark's nutcrackers have been observed to frequently cache whitebark pine seeds within $100 \mathrm{~m}$ of whitebark pine canopies (Hutchins and Lanner 1982, Lorenz et al. 2011). To address our second objective, we constructed models of whitebark pine seedling presence and identified important predictor variables. Based on the results of several previous studies, summarized above, we expected that forest type, elevation, temperature, precipitation, and cover of $V$. scoparium would be important predictors of seedling presence.

\section{Methods}

\section{Study Area and Sampling Methods}

To assess whitebark pine seedling occurrence at the landscape level, we acquired field data collected from USDA Forest Service Forest Inventory and Analysis (FIA) plots. We defined the study area as the region within the phylogenetic seed zones of whitebark pine (Mahalovich and Hipkins 2011) in the US Rocky Mountains, which encompasses the extent of whitebark pine observed on FIA plots, including those outside Little's (1971) whitebark pine distribution map (Figure 1). The sample consisted of 7,018 forest plots that were measured between 2006 and 2015. Plot measurements collected prior to 2006 were not included to maintain the independence of observations among plots, given that FIA remeasures each plot every 10 years. FIA plot locations comprise a probabilistic sample with a spatial intensity of approximately one plot per 6,000 acres $(2,428 \mathrm{ha})$ across all land cover types, forest types (described in O'Connell et al. 2016), and ownership groups (Bechtold and Patterson 2005).

Whitebark pine seedling density and numerous site factors were measured on each FIA plot. Each FIA plot contains four subplots of $24-\mathrm{ft}(7.3-\mathrm{m})$ radius, where each plot may contain multiple forest types (USDA 2013). To avoid nonindependence among sample units, our analysis evaluated plots as sample units; for plots with multiple forest types, we characterized the plot's forest type as the type occupying the majority of the plot area. Within each subplot, saplings (1.0-4.99 in, or $2.5-12.7 \mathrm{~cm}$, diameter at breast height) and seedlings $(<1.0$ inch, or $2.5 \mathrm{~cm}$, diameter at breast height and $\geq 6.0 \mathrm{in}$, or $15.2 \mathrm{~cm}$, in length) are measured on a microplot of 6.8-ft (2.1-m) radius (USDA 2013). Within each microplot, field crews counted the number of seedlings for each species present (USDA 2013). Due to whitebark pine's slow growth rate, seedling tallies represent individuals that may have germinated several years prior to measurement. The small size of the microplots may lead to underestimation of spatially clumped seedlings, which may occur with whitebark pine (Tomback et al. 1993).

Forest types were determined from field-recorded dominance based on stocking (i.e., FLDTYPCD in O'Connell et al. 2016). When no live trees occur on a plot, FLDTYPCD is assigned based

\section{Management and Policy Implications}

Whitebark pine (Pinus albicaulis Engelm.) has recently experienced high mortality due to a combination of heat, drought, white pine blister rust (Cronartium ribicola), mountain pine beetle (Dendroctonus ponderosae Hopkins), and alteration of fire regimes. The future of whitebark pine, and the numerous wildlife species that depend upon it, may rely on management strategies that encourage natural regeneration and facilitate recruitment of young trees from seedling to larger size classes. Thus, it is critical to understand where natural regeneration is occurring and identify the characteristics of these sites. To meet this need, we assessed the density of whitebark pine seedlings in different forest types and modeled whitebark pine seedling presence from climate and site data throughout the US Rocky Mountains. Most sites with seedlings present (83\%) occurred in forest types other than whitebark pine, primarily in lodgepole pine and Engelmann spruce/subalpine fir forest types. Based on our models, seedlings are most likely to occur at sites where whitebark pine occurs in the overstory, where grouse whortleberry (Vaccinium scoparium Leiberg ex (oville) is present, and at relatively high elevations. Unexpectedly, forest type and metrics of forest density are not important predictors of whitebark pine seedling presence. Management objectives that seek to facilitate recruitment of whitebark pine seedlings into larger size classes may be well served to target multiple forest types with a whitebark pine component and focus on creating canopy gaps that may lead to competitive release of young whitebark pines. 


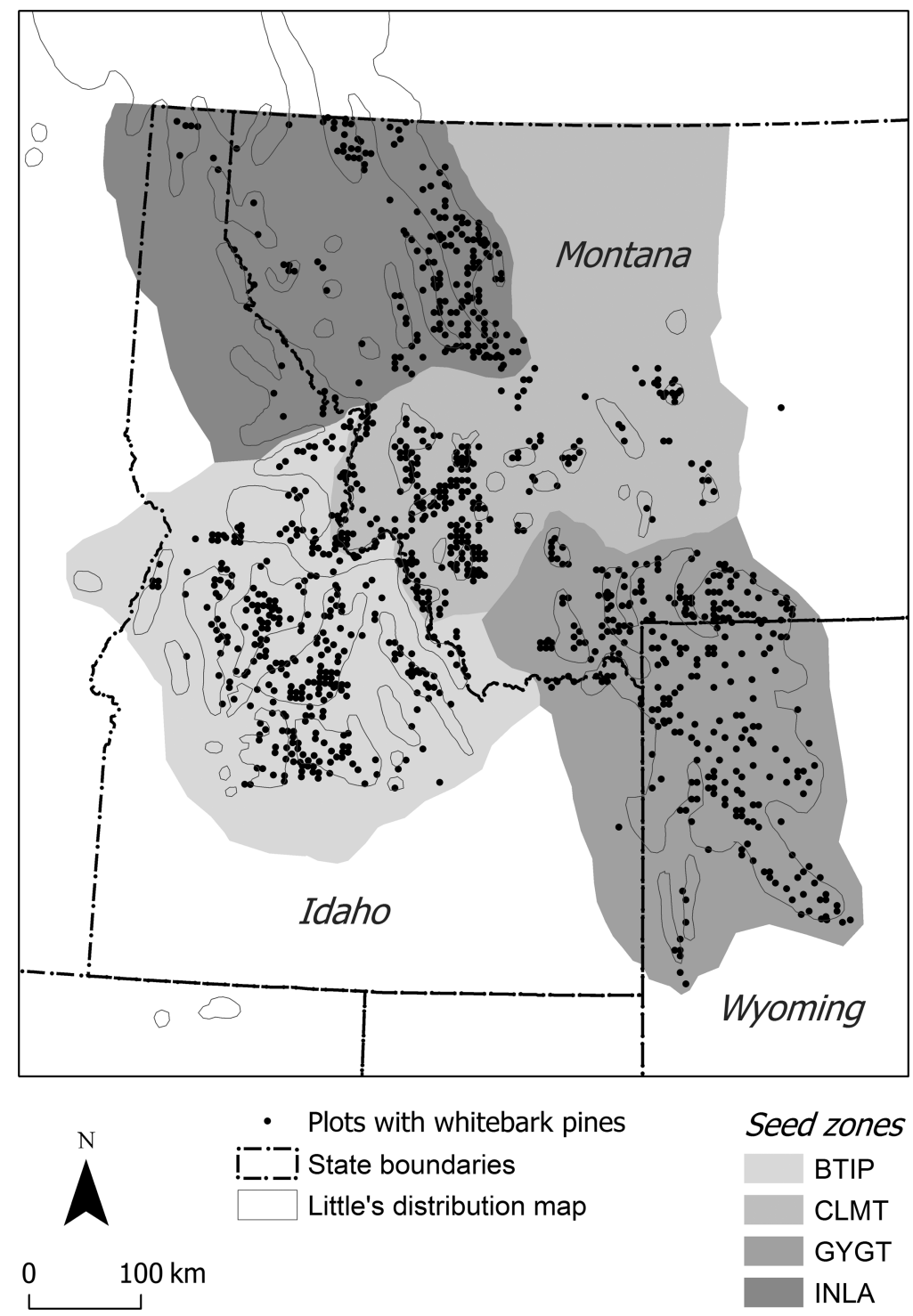

Figure 1. Approximate locations of 1,217 plots with a whitebark pine component (black dots) used for characterizing seedling density within the US portion of the northern Rocky Mountains. Shaded areas represent four whitebark pine phylogenetic seed zones (Mahalovich and Hipkins 2011) that were used to define the domain of our study: Inland Northwest (INLA), Central Montana (CLMT), Bitterroots-Idaho Plateau (BTIP), and Greater Yellowstone-Grand Teton (GYGT). Black outlines represent a 50-km buffer around Little's (1971) distribution of whitebark pine, which is less inclusive than the seed zones.

on seedlings, if any are present, or on trees in the same stand that are outside the plot footprint. We decided to use field-recorded forest type rather than forest type as calculated by FIA's stocking-based forest type algorithms (i.e., FORTYPCD in O'Connell et al. 2016) because the latter assign a forest-type of "nonstocked" when stocking is $<10 \%$ (O'Connell et al. 2016), which is common in whitebark pine stands. Whitebark pine often occurs at sites that have experienced high recent mortality and therefore frequently occupies sites with $<10 \%$ live stocking.

Only forest types that occurred on at least $5 \%$ of plots with a whitebark pine component were explicitly represented in our analysis, and all other forest types-which each represented $<1 \%$ of plots with a whitebark pine component-were lumped into "other" forest type. Thus, possible values of forest type include: whitebark pine, lodgepole pine, subalpine fir, subalpine fir/Engelmann spruce, Douglas-fir, and "other" forest type. To investigate whether forest type classifications were likely to have changed due to recent whitebark pine mortality, we examined total live and dead basal area of whitebark pine by forest type.

\section{Seedling Density across Forest Types}

To assess the density and distribution of whitebark pine regeneration, we constrained the analysis domain to 1,217 plots that had a whitebark pine component, which was defined as any plot with any combination of at least one whitebark pine seedling $(\geq 6.0$ in $[15.2 \mathrm{~cm}]$ tall), at least one live whitebark pine tree $\geq 1.0$ in $(2.5 \mathrm{~cm})$ diameter, or at least one dead whitebark pine tree $\geq 5.0$ in $(12.7 \mathrm{~cm})$ diameter. We calculated median seedling density and quantiles for all plots with a whitebark pine component and then for individual forest types within the study area, where forest types were classified as described above. We tested for significant differences in whitebark pine seedling density among forest types using Dunn's test for multiple comparisons (Zar 1996) with $\alpha=0.05$. 
Previous research demonstrated that a large proportion of sites with whitebark pine seedlings present occurred in non-whitebark pine forest types (Goeking and Izlar 2018), which raised the question: did the forest-type classification of these sites shift from the whitebark pine forest type to another type as a result of recent whitebark pine mortality? To answer this question, we calculated the total amount of live plus dead whitebark pine basal area at each site. If a substantial number of sites had experienced sufficient whitebark pine mortality to result in reclassification from whitebark pine to a different forest type, we expected that there would be overlap in the amount of total whitebark pine basal area among forest types. We used Dunn's nonparametric test for multiple comparisons (Zar 1996) to test for differences in total (live plus dead) whitebark pine basal area among forest types $(\alpha=0.05)$.

\section{Seedling Presence Models}

To identify significant predictors of where whitebark pine seedlings are likely to occur, we used data from the 1,217 plots with a whitebark pine component to construct three statistical models of whitebark pine seedling presence: logistic regression, classification trees, and random forests. We reclassified the FIA seedling count data as a binary (presence/absence) response variable for each plot, where presence of a whitebark seedling on any of the four subplots qualified as a presence for the plot. The purpose of using three distinct models was to use the aggregated results of the models to identify common factors that are related to seedling presence regardless of model structure. Logistic regression was included because it allows evaluation of each variable's importance by means of z-scores and their associated $p$ values. Classification trees and random forests were included because they make no a priori assumptions about the distributions of response or predictor variables, they provide intuitive interpretation of variable importance, and they typically perform well even when predictor variables are collinear or interact to affect the response variable (Cutler et al. 2007). All three models were developed in $\mathrm{R}$ ( $\mathrm{R}$ Core Team 2016) with a classification threshold of 0.5 .

The initial models included 50 predictor variables, some of which are collinear, in six broad descriptive categories (Table 1). The descriptive categories were not included in the analysis but merely provide a framework for describing and interpreting the numerous predictors. Most abiotic variables (e.g., slope) and biotic variables (e.g., live canopy cover) were measured on FIA plots as described in USDA Forest Service (2013) and O'Connell et al. (2016). Forest density was represented quantitatively as basal area and percent canopy cover. Rather than include indicators of all potential understory species in our models, we used previous research (Forcella and Weaver 1977, Tomback et al. 1993, Goeking and Izlar 2014) to narrow the number of predictor variables to percent cover of the following species: Vaccinium scoparium, all Carex spp., and Juniperus communis. Additionally, we included aggregate cover of understory vegetation by life form (forbs, graminoids, shrubs, and trees) as well as seedling density of other major tree species that co-occur with whitebark pine. Folded aspect and heat load were calculated from field measurements (McCune and Keon 2002). Equivalent elevation was calculated by adding $129.4 \mathrm{~m}$ to absolute elevation for every 1-degree difference from the minimum latitude among all plots (Windmuller-Campione and Long 2016). Ombrothermic index (Rivas-Martínez et al. 1999) and seasonal climate variables were calculated from monthly PRISM data (Daly 1994; PRISM Climate Group 2012). Seed zone was derived from a 4-class phylogenetic seed zone map, which represents genetic resistance to disease and other environmental stressors (Mahalovich and Hipkins 2011). Management effect indicates whether the plot is in a reserved area (e.g., national park or wilderness area), and time effect is the year of plot measurement.

Logistic regression was implemented as a generalized linear model with a logit link and binomial family in function glm in baseR (Hastie et al. 2016, R Core Team 2016). To meet the model's assumption of noncollinearity among predictor variables (James et al. 2013, Kuhn and Johnson 2016), we reduced the dimensionality of the dataset via principal components analysis. Because the predictor variables were measured on varying numeric scales and because variance had a wide range of values among predictor variables, we used the correlation matrix rather than covariance matrix as the basis of principal components analysis. The percent of variance explained was calculated as each principal component's (PC's) eigenvalue divided by the sum of all components' eigenvalues. The four PCs that each explained $>5 \%$ of the variance were included in lieu of their related predictor variables, which were identified as variables with PC loadings of at least 0.25 (Table 2). The logistic regression model of whitebark pine seedling presence included these four PCs plus all original predictor variables minus the ones associated with PC1, PC2, PC3, or PC4 (Table 2).

A basic classification tree was constructed using $\mathrm{R}$ package rpart, Recursive Partitioning, and Regression Trees (Therneau et al. 2015). We selected the appropriate complexity parameter (CP) for the classification tree by examining a CP plot (Therneau et al. 2015), or prediction error curve (Hastie et al. 2016), and identifying the maximum value of the complexity parameter associated with relative error of less than one standard error (Breiman et al. 1984). We then reconstructed the classification tree using the selected complexity parameter $(C P=0.017)$. We developed the random forests model (Breiman 2001) in R package randomForests (Liaw and Wiener 2002) where parameter ntree $=500$ trees and mtry $=7$ (i.e., 7 variables were considered for each split).

We assessed each model's performance using 10-fold cross-validation (James et al. 2013) and subsequent comparison of percent correctly classified; Cohen's kappa; true skill statistic (TSS), which may be more appropriate than kappa given the unbalanced frequency of seedling presences versus absences (Allouche et al. 2006); area under the receiver-operator curve (AUC); the false presence rate (i.e., commission error); sensitivity; and specificity among all models. False presence rates were particularly useful performance metrics because we assumed that managers would prefer to have a high likelihood of finding seedlings when presence is predicted by the models.

\section{Factors Related to Seedling Presence}

We identified important predictors of whitebark pine seedling presence using methods appropriate to each type of model and compared the results across all models. Important predictors are defined here as variables that were statistically significant predictors in at least one model. For the logistic regression model, we detected significant predictors using $p(|z|)<0.01$ (i.e., variable coefficients significantly different than 0 based on z scores) and identified variables associated with any PCs that were recognized as significant 
Table 1. Initial predictor variables evaluated for inclusion in whitebark pine seedling presence models, by descriptive category.

\begin{tabular}{|c|c|c|c|c|}
\hline Predictor group & Description & Code & Source & Type \\
\hline \multirow[t]{8}{*}{ Abiotic site variable } & Disturbance type $(\text { code })^{1}$ & DSTRBCD1 & Derived from FIA data & Factor \\
\hline & Ecoregion subprovince $^{2}$ & ECOPROV & FIA data (ECOPROV) & Factor \\
\hline & Equivalent elevation adjusted for latitude & ELEV_EQV & Derived from $\mathrm{DEM}^{6}$ & Numeric \\
\hline & Aspect (folded about a north-south axis) & FOLDASP & Derived from $\mathrm{DEM}^{6}$ & Numeric \\
\hline & Heat load index (McCune and Keon 2002) & HEATLOAD & Derived from $\mathrm{DEM}^{6}$ & Numeric \\
\hline & Latitude & LAT_FUZZED & FIA data (LAT_FUZZED) & Numeric \\
\hline & Longitude & LON_FUZZED & FIA data (LON_FUZZED) & Numeric \\
\hline & Slope (percent) & SLOPE & FIA data (SLOPE) & Numeric \\
\hline \multirow{26}{*}{ Biotic stand variable } & Stand-size class ${ }^{3}$ & STDSZCD & FIA data (STDSZCD) & Factor \\
\hline & Forest type (field designation) $)^{4}$ & FLDTYPCD & FIA data (FLDTYPCD) & Factor \\
\hline & Dead basal area, all species (sq ft/acre) & BA_DEAD & Derived from FIA data & Numeric \\
\hline & Dead basal area, wbp (sq ft/acre) & BA_DEAD_WBP & Derived from FIA data & Numeric \\
\hline & Live basal area, all species (sq ft/acre) & BA_LIVE & Derived from FIA data & Numeric \\
\hline & Live basal area, whitebark pine (sq ft/acre) & BA_LIVE_WBP & Derived from FIA data & Numeric \\
\hline & Live canopy cover (percent) & CC_LIVE & Derived from FIA data & Numeric \\
\hline & Live and missing canopy cover (percent) & CC_LM & Derived from FIA data & Numeric \\
\hline & Mortality canopy cover (percent) & CC_M & Derived from FIA data & Numeric \\
\hline & Cover of Carex spp. (percent) & COV_CAREX & Derived from FIA data & Numeric \\
\hline & Cover of all forbs (percent) & COV_FB & Derived from $\mathrm{DEM}^{5}$ & Numeric \\
\hline & Cover of all graminoids (percent) & COV_GR & Derived from FIA data & Numeric \\
\hline & Cover of Juniperus communis (percent) & COV_JUCO & Derived from FIA data & Numeric \\
\hline & Cover of all shrubs (percent) & COV_SH & Derived from FIA data & Numeric \\
\hline & Cover of all trees (percent) & COV_TT & FIA data & Numeric \\
\hline & Cover of Vaccinium scoparium (percent) & COV_VASC & Derived from FIA data & Numeric \\
\hline & Growth of all species $\left(\mathrm{ft}^{3} \mathrm{ac}^{-1} \mathrm{yr}^{-1}\right)$ & GROW_PA & Derived from FIA data & Numeric \\
\hline & Mortality of all species $\left(\mathrm{ft}^{3} \mathrm{ac}^{-1} \mathrm{yr}^{-1}\right)$ & MORT_PA & Derived from FIA data & Numeric \\
\hline & Stand age (years) & STDAGE & FIA data (STDAGE) & Numeric \\
\hline & Live and dead trees per acre & TPA_ALL & Derived from FIA data & Numeric \\
\hline & Live trees per acre & TPA_LIVE & FIA data & Numeric \\
\hline & Seedlings/acre of Abies lasiocarpa & SEED̄__TPA_ABLA & FIA data & Numeric \\
\hline & Seedlings/acre of all other tree species & SEEDS_TPA_OTH & FIA data & Numeric \\
\hline & Seedlings/acre of Pinus contorta & SEEDS_TPA_PICO & FIA data & Numeric \\
\hline & Seedlings/acre of Picea engelmannii & SEEDS_TPA_PIEN & FIA data & Numeric \\
\hline & Seedlings/acre of Pseudotsuga menziesii & SEEDS_TPA_PSME & FIA data & Numeric \\
\hline \multirow[t]{13}{*}{ Climatic variable } & Ombrothermic index ${ }^{5}$ & OMBRO_IINDX & Derived from PRISM data ${ }^{7}$ & Numeric \\
\hline & Total autumn precipitation & PPT_AUT & Derived from PRISM data ${ }^{7}$ & Numeric \\
\hline & Total spring precipitation & PPT_SPR & Derived from PRISM data ${ }^{7}$ & Numeric \\
\hline & Total summer precipitation & PPT_SUM & Derived from PRISM data ${ }^{7}$ & Numeric \\
\hline & Total winter precipitation & PPT_WIN & Derived from PRISM data ${ }^{7}$ & Numeric \\
\hline & Maximum autumn temperature & TMĀX_AUT & Derived from PRISM data ${ }^{7}$ & Numeric \\
\hline & Maximum spring temperature & TMAX_SPR & Derived from PRISM data ${ }^{7}$ & Numeric \\
\hline & Maximum summer temperature & TMAX_SUM & Derived from PRISM data ${ }^{7}$ & Numeric \\
\hline & Maximum winter temperature & TMAX_WIN & Derived from PRISM data ${ }^{7}$ & Numeric \\
\hline & Minimum autumn temperature & TMIN_AUT & Derived from PRISM data ${ }^{7}$ & Numeric \\
\hline & Minimum spring temperature & TMIN SPR & Derived from PRISM data ${ }^{7}$ & Numeric \\
\hline & Minimum summer temperature & TMIN_SUM & Derived from PRISM data ${ }^{7}$ & Numeric \\
\hline & Minimum winter temperature & TMIN_WIN & Derived from PRISM data ${ }^{7}$ & Numeric \\
\hline Management effect & Reserved status (reserved or not reserved) & RESERVCD & FIA data (RESERVCD) & Factor \\
\hline Seed zone & Seed zone (categories shown in Fig. 1) & SEEDZONE & Mahavolich \& Hipkins (2011) & Factor \\
\hline Time effect & Measurement year & MEASYEAR & FIA data (MEASYEAR) & Numeric \\
\hline
\end{tabular}

${ }^{1}$ Disturbance types included insects, disease, fire, and other disturbance.

${ }^{2}$ Ecoprovinces included five map units within the Temperate Steppe Division (including Mountain Provinces) of Cleland et al. (2007).

${ }^{3}$ Stand-size classes included small, medium, and large-diameter trees (see O'Connell et al. 2017), as well as nonstocked.

${ }^{4}$ Field-assigned forest types included whitebark pine, lodgepole pine, subalpine fir, subalpine fir/Engelmann spruce, Douglas-fir, and other type.

${ }^{5}$ Rivas-Martínez et al. (1999).

${ }^{6}$ Digital Elevation Model from the National Elevation Dataset.

${ }^{7}$ Daly (1994); PRISM (2012).

Table 2. Four principal components included in the logistic regression model, percent of variance explained, and predictor variables with loadings $>0.25$ (direction of correlation between each PC and associated predictor variable in parentheses). Variables are described in Table 1.

\begin{tabular}{lll}
\hline PC & \% Variance explained & Variables with highest loadings $(>\mathbf{0 . 2 5})$ \\
\hline PC1 & $21.9 \%$ & ELEV_EQV (-), TMAX_[all seasons] (+), TMIN_[all seasons] (+) \\
PC2 & $12.4 \%$ & CC_LIVE $(+)$, BA_LIVE (+), PPT_AUT (+), PPT_WIN (+), PPT_SPR (+) \\
PC3 & $8.5 \%$ & CC_LIVE (+), TPA_LIVE (+), TPA_ALL (+),PPT_AUT (-), PPT_WIN (-), PPT_SPR (-) \\
PC4 & $5.7 \%$ & CC_LM (-), CC_M(-), BA_DEAD (-), MORT_PA (-), GROW_PA (+), SEEDS_TPA_OTH (-) \\
Total & $48.5 \%$ & \\
\hline
\end{tabular}


predictors. For the classification tree, we identified significant predictor variables from the nodes of the final classification tree. Significant variables in the random forests model were identified by their corresponding mean decreases in overall accuracy and Gini index (Cutler et al. 2007, James et al. 2013).

\section{Results}

\section{Seedling Density across Forest Types}

The prevalence of sites with whitebark pine seedlings varied with respect to presence of whitebark pine trees and by forest type. Of the 7,018 FIA plots included in this analysis, 1,217 (17\%) had a whitebark pine component and 795 plots had whitebark pine seedlings present. Median seedling density, including the 422 plots with no seedlings present, was 150 seedlings per acre (Figure 2). Although median seeding density was highest in the whitebark pine forest type (Figure 3a), it was not significantly different in the whitebark pine versus lodgepole pine forest types. The highest densities of whitebark pine seedlings occurred within the lodgepole pine forest type $(6,447$ seedlings/ac, or 15,931 seedlings/ha). Of the 795 plots where seedlings occurred, only 16\% (126) occurred within the whitebark pine forest type, 35\% (281 plots) occurred within the lodgepole pine forest type, $20 \%$ in subalpine fir forest type, 23\% in Engelmann spruce/subalpine fir forest type, 6\% in Douglas-fir forest type, and $<1 \%$ in other forest types. Thus, approximately $83 \%$ of sites where whitebark pine seedlings occur fall within non-whitebark pine forest types.

The amount of live plus dead whitebark pine basal area did not support the contention that sites in non-whitebark pine forest types experienced a forest-type change due to recent whitebark pine mortality (Figure 3b). Although a few outliers (plots) classified as subalpine fir or Engelmann spruce/subalpine fir forest types had large amounts of total (live plus dead) whitebark pine basal area, nonwhitebark pine forest types had significantly lower total whitebark pine basal area than the whitebark pine forest type (Figure 3b). This suggests that forest-type classifications of plots with a whitebark pine component have not changed appreciably due to recent whitebark pine mortality. Therefore, the density of whitebark pine seedlings by forest type likely represents conditions over the past decade or longer.

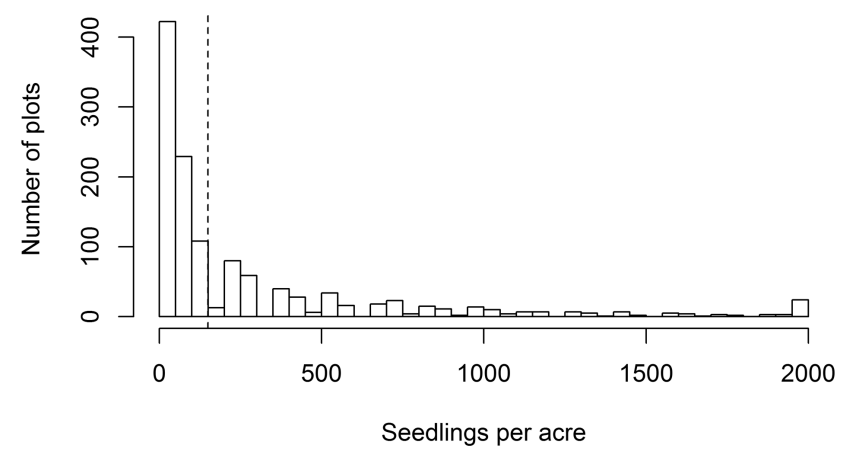

Figure. 2. Histogram of whitebark pine seedling density at 1,217 FIA plots with a whitebark pine component (live seedling $\geq 6$ in [15.2 cm] tall, live sapling $\geq 1$ in [2.5 cm] diameter, or live or dead tree $\geq 5$ in $[12.7 \mathrm{~cm}]$ diameter). Bin width $=50$ seedlings/acre $(124$ seedlings/ha). Dotted vertical line indicates median of 150 whitebark pine seedlings/acre ( 371 seedlings/ha). Far left bar represents $\mathbf{4 2 2}$ plots with 0 seedlings, and far right bar represents 24 plots with $>2,000$ seedlings/acre.

\section{Seedling Presence Models}

The logistic regression model included PCs that explained $48.5 \%$ of total variation (Table 2). PC1 explained $21.9 \%$ of total variation and was negatively related to elevation and positively related to temperature. PC2 was positively related to live canopy cover and seasonal precipitation, except for summer precipitation. PC3 was positively related to live canopy cover and tree density, yet negatively related to seasonal precipitation, again except for summer precipitation. PC4 was negatively associated with measures of recent mortality, dead tree density, and total seedling density of all species other than whitebark pine and positively associated with net tree growth; this PC explained only $5.7 \%$ of total variation. Collectively, the variables associated with PC4 likely indicated recent disturbance.

The logistic regression, classification tree, and random forests models all exhibited similar model performance (Table 3). Percent correctly classified, or overall accuracy, differed by $<1 \%$ among all

(a)

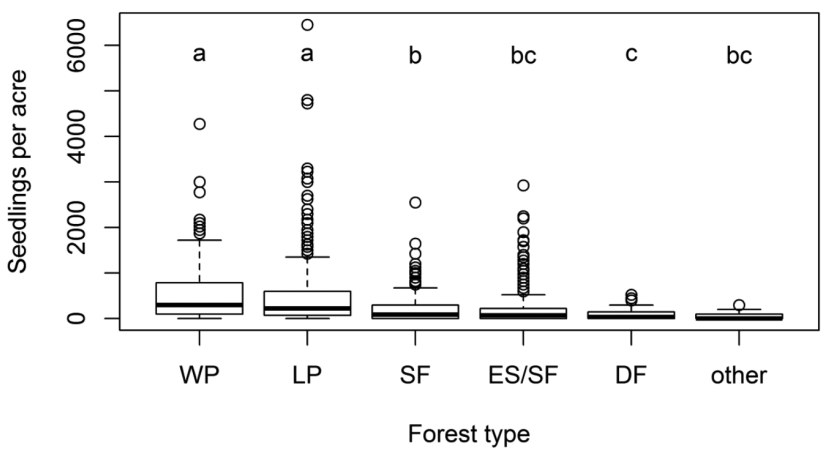

(b)

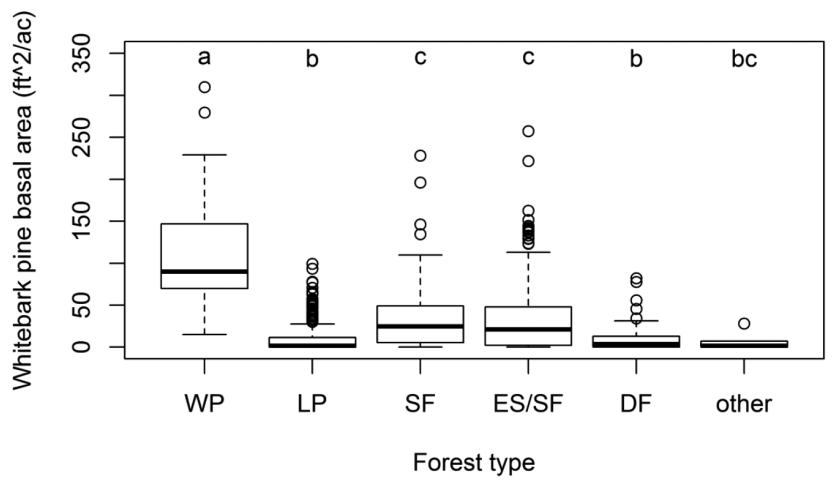

Figure. 3. (a) Boxplot of whitebark pine seedling density by FIA fieldrecorded forest type. Forest type are abbreviated as: WP, whitebark pine; LP, lodgepole pine; SF, subalpine fir; ES/SF, Engelmann spruce/subalpine fir; DF, Douglas-fir; other, all other forest types combined. Horizontal lines within boxes represent median whitebark pine seedling density. Vertical box boundaries represent first and third quartiles (25th and 75th percentiles, respectively). Horizontal lines at ends of vertical dashed lines represent 1.5x the interquartile range, and circles represent plots beyond the interquartile range. (b) Boxplot of total basal area of whitebark pine trees, including both live and dead trees, by forest type. Forest type abbreviations, as well as interpretation of boxes, lines, and circles, are as in (a). In both (a) and (b), letters indicate statistically nonsignificant differences among forest types based on Dunn's test for multiple comparisons (Zar 1996) with $\alpha=0.05$. 
Table 3. Confusion matrices and performance metrics for each statistical model.

\begin{tabular}{|c|c|c|c|c|c|c|}
\hline \multirow{2}{*}{$\frac{\text { Model }}{\text { Logistic regression }}$} & & \multicolumn{3}{|c|}{ Confusion matrix } & \multicolumn{2}{|c|}{ Performance metrics } \\
\hline & \multirow{7}{*}{ Observed } & & & & PCC & 0.923 \\
\hline & & & Predicted & & TSS & 0.489 \\
\hline & & & A & $\mathrm{P}$ & Kappa & 0.561 \\
\hline & & A & 6071 & 152 & AUC & 0.940 \\
\hline & & $\mathrm{P}$ & 387 & 408 & $\mathrm{FP}$ & 0.024 \\
\hline & & & & & Sensitivity & 0.513 \\
\hline & & & & & Specificity & 0.976 \\
\hline \multirow[t]{7}{*}{ Classification tree } & & & & & PCC & 0.929 \\
\hline & & & Predicted & & TSS & 0.534 \\
\hline & & & & $\mathrm{P}$ & Карра & 0.602 \\
\hline & Observed & A & 6077 & 146 & AUC & 0.790 \\
\hline & & $\mathrm{P}$ & 352 & 443 & FP & 0.023 \\
\hline & & & & & Sensitivity & 0.557 \\
\hline & & & & & Specificity & 0.977 \\
\hline \multirow[t]{7}{*}{ Random forests } & & & & & PCC & 0.932 \\
\hline & & & Predicted & & TSS & 0.540 \\
\hline & & & & $\mathrm{P}$ & Карра & 0.614 \\
\hline & Observed & A & 6092 & 131 & AUC & 0.959 \\
\hline & & $\mathrm{P}$ & 349 & 446 & $\mathrm{FP}$ & 0.021 \\
\hline & & & & & Sensitivity & 0.561 \\
\hline & & & & & Specificity & 0.979 \\
\hline
\end{tabular}

A, absence; P, presence; PCC, percent correctly classified; Kappa, Cohen's kappa; TSS, true skill statistic; AUC, area under receiver-operator curve; FP, false presence rate (equal to 1.0 minus specificity).

three models (92.3\% to 93.2\%). Kappa ranged from 0.561 (logistic regression) to 0.614 (random forests), TSS ranged from 0.489 (logistic regression) to 0.540 (random forests), and AUC ranged from 0.790 (classification tree) to 0.959 (random forests). The false presence rate was lowest for random forests $(2.1 \%)$ and highest for logistic regression (2.4\%). Sensitivity was $<0.6$ for all models, indicating that all models underpredict the presence of whitebark pine seedlings, and specificity was high ( $>0.97)$ for all models. Both sensitivity and specificity were slightly higher for random forests than for logistic regression or classification tree. Based on these collective results, the random forests model performed slightly better than logistic regression and classification trees.

\section{Factors Related to Seedling Presence}

All three models indicated that $V$. scoparium cover is significantly and positively associated with whitebark pine seedling presence (Table 4). Two of the models (random forests and logistic regression) identified high dead whitebark pine basal area and high equivalent elevation as important predictors. The random forests model also recognized low seasonal temperatures, and the importance of PC1 in the logistic regression corroborates the importance of seasonal temperature and elevation. Two models (classification tree and random forests) distinguished high live whitebark pine basal area. None of the models discriminated among the whitebark pine, lodgepole pine, subalpine fir, or Engelmann spruce/subalpine fir forest types. Overall stand density of all species and precipitation were associated with two significant predictors-PC2 and PC4, respectively_but were not significant as individual variables.

In the logistic regression model, numerous variables had coefficients that differed significantly from zero and were thus deemed important predictors (Table 4). Density of $V$. scoparium, density of subalpine fir (Abies lasiocarpa (Hook.) Nutt.) and Douglas-fir (Pseudotsuga menziesii (Mirb.) Franco) seedlings, cover of small understory trees, and dead whitebark pine basal area were positively related to whitebark pine seedling presence. Total shrub cover, ombrothermic index, and longitude were negatively related to whitebark pine seedling presence. The categorical variables representing seed zone, stand-size class, reserved status, and forest type were also important predictors. Interpretation of these categorical variables indicates that whitebark pine seedlings are most likely to occur in the Greater Yellowstone/Grand Teton phylogenetic seed zone (see Figure 1); in forest types dominated by whitebark pine, subalpine fir, Engelmann spruce/subalpine fir, or lodgepole pine; in stands of relatively small trees $(<9$ " $[22.9 \mathrm{~cm}]$ diameter $)$; and outside reserved areas such as national parks or wilderness areas. Three principal components- $\mathrm{PC} 1, \mathrm{PC} 2$, and $\mathrm{PC} 4$-were recognized as important predictors of seedling presence (Table 4).

The classification tree (Figure 4) indicates that first, seedlings occur where mature whitebark pines are present, and second, sites that are favorable for $V$. scoparium and for lodgepole pine (Pinus contorta Douglas ex Loudon) seedlings are also favorable for whitebark pine seedlings. The model specifically predicts that whitebark pine seedlings are most likely to occur at sites with at least $0.2 \mathrm{ft}^{2} /$ acre $\left(0.046 \mathrm{~m}^{2} / \mathrm{ha}\right)$ of live whitebark pine basal area, at least $2.4 \%$ cover of $V$. scoparium, and at least 84 lodgepole pine seedlings per acre (208 seedlings/ha).

Important variables in the random forests model included, in decreasing order of importance based on their effect on overall accuracy, live whitebark pine basal area, equivalent elevation, dead whitebark pine basal area, maximum spring temperature, $V . s c o-$ parium cover, and several seasonal temperature variables (Figure 5). Maximum temperatures in each season were generally more important than minimum temperatures (Figure 5).

\section{Discussion}

A main objective of this study was to assess whitebark pine seedling densities throughout the US Rocky Mountains, and we found that $83 \%$ of sites with naturally occurring whitebark pine regeneration occur in stands outside the whitebark pine forest type. Thus, if a goal of forest management is to facilitate natural whitebark pine regeneration, then targeting only the whitebark pine forest type (i.e., stands dominated by whitebark pines) may be insufficient. The 
Table 4. Significant predictors of whitebark pine seedling presence, as determined from logistic regression $(P<0.01)$, classification tree (variables at nodes), and random forests models (mean decrease in accuracy $>0.005$ ).

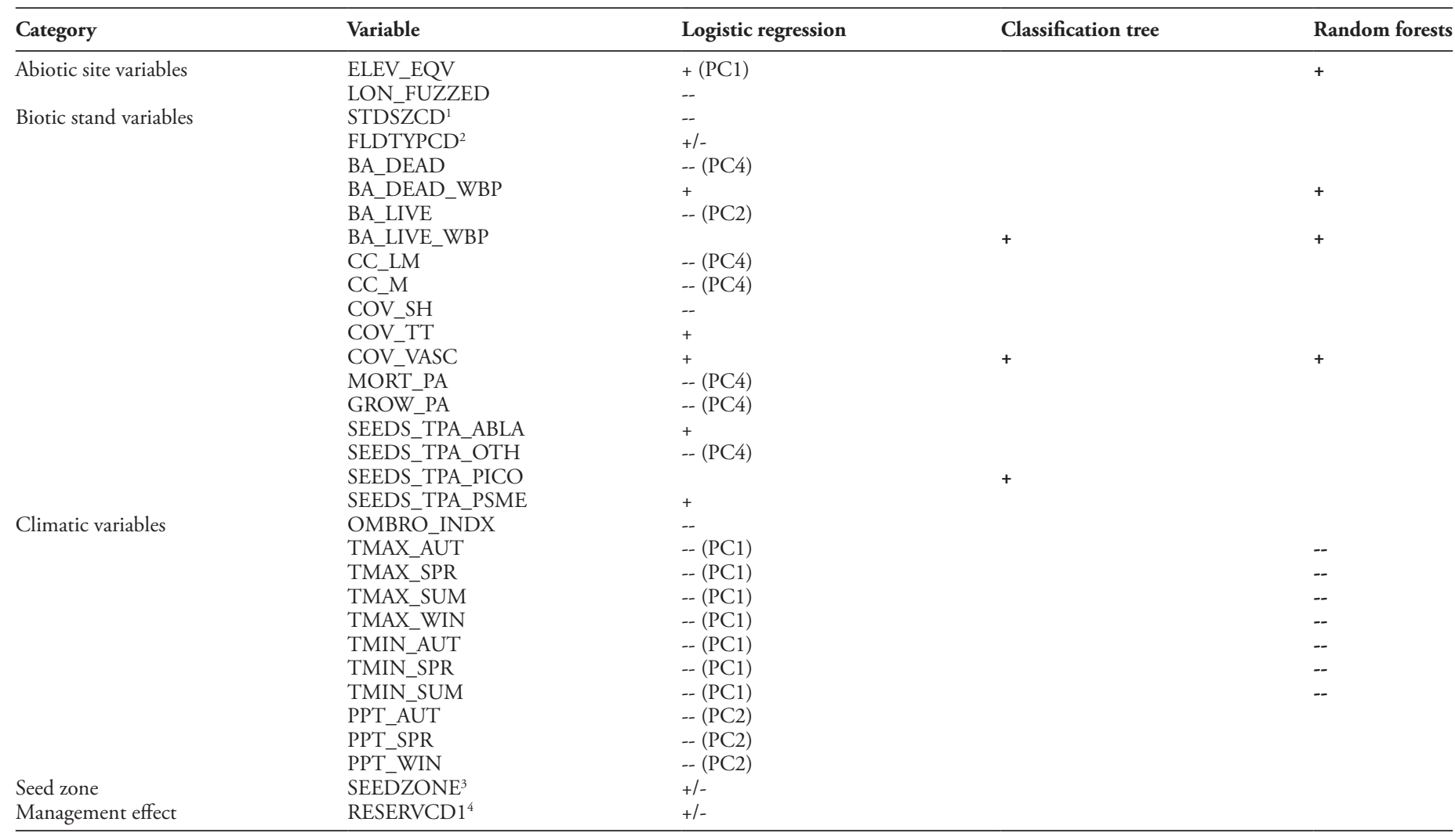

Symbols indicate a positive (+) or negative (--) relationship with whitebark pine seedling presence. See Table 1 for variable descriptions; see Table 2 for PC descriptions. Variables from Table 1 not shown here did not emerge as significant in any of the three models.

'Only stand-size class "nonstocked" had a significant coefficient, which was negative.

${ }^{2}$ Forest types with significant (positive) coefficients were whitebark pine, lodgepole pine, spruce-fir, and fir.

${ }^{3}$ Only seed zones CLMT and INLA had significant coefficients; both were positive.

${ }^{4}$ Reserved areas had a significant and positive coefficient.

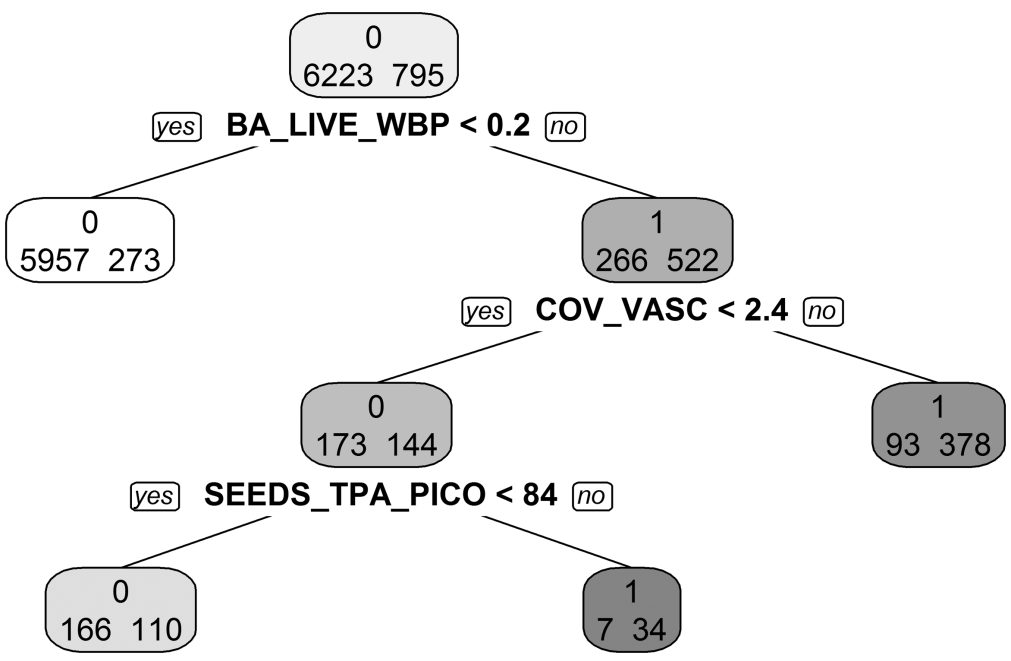

Figure. 4. Classification tree predicting whitebark pine seedling presence, with complex parameter $(C P)=0.017$. BA_LIVE_WBP, live whitebark pine basal area $\left(\mathrm{ft}^{2} / \mathrm{ac}\right)$. COV_VASC, percent cover of grouse whortleberry (Vaccinium scoparium). SEEDS_TPA_PICO, seedlings per acre of lodgepole pine (Pinus contorta).

vast majority of sites with whitebark pine seedlings occur in other forest types, specifically in stands dominated by lodgepole pine, subalpine fir, or Engelmann spruce, as indicated by forest-type classifications that represent $50 \%$ stocking or greater by these species
(O’Connell et al. 2016). Whitebark pine seedling densities were not significantly different between whitebark pine and lodgepole pine forest types, and maximum seedling densities were observed in stands dominated by lodgepole pine. This somewhat contradicts 


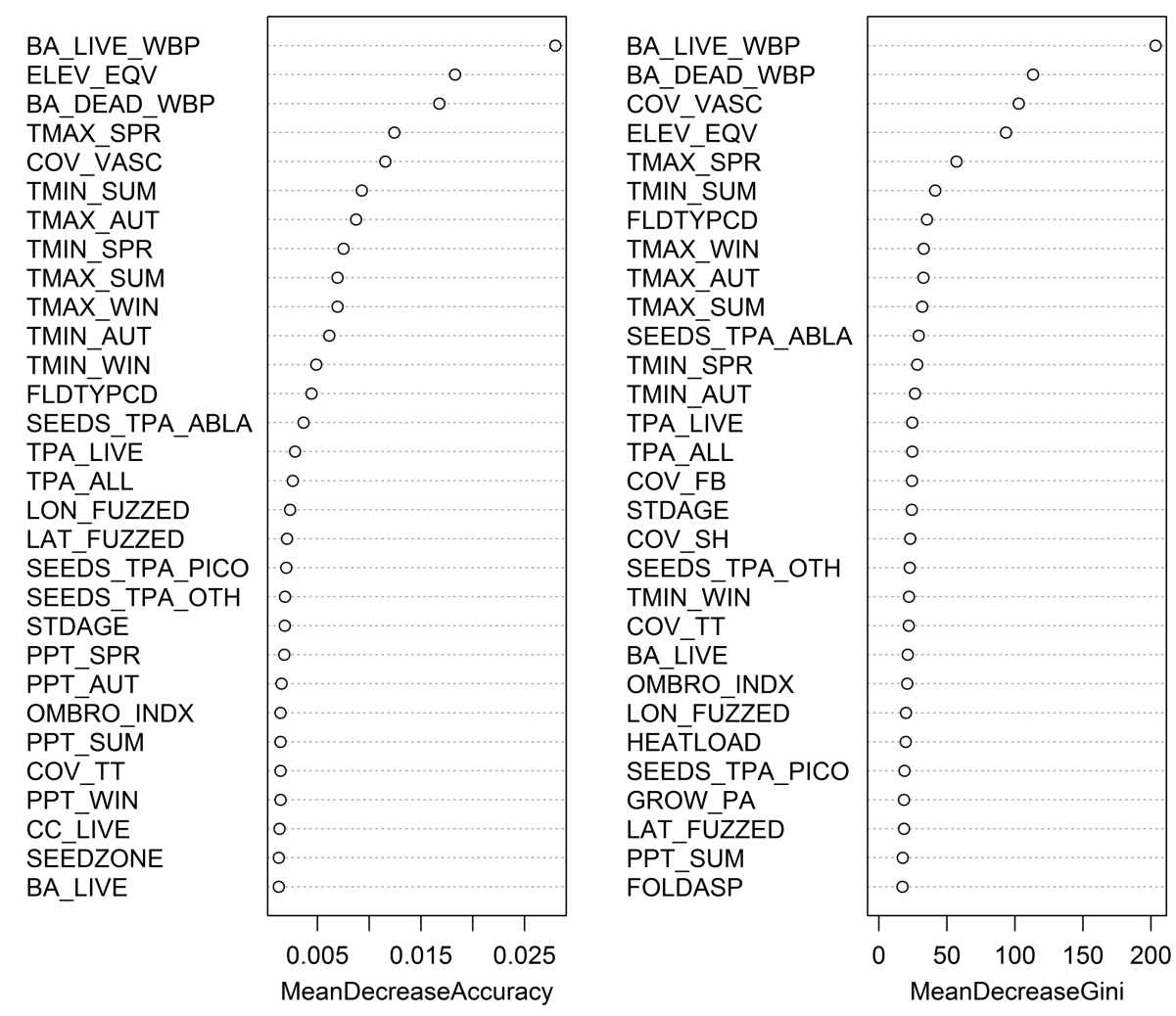

Figure. 5. Variable importance plots produced by random forests measured as each variable's (Table 1) mean decrease in overall accuracy (left) and the Gini index (right). The most important predictor variables have the highest decrease in overall accuracy.

previous research suggesting that whitebark pine seedling recruitment was highest in stands dominated by whitebark pine (Larson and Kipfmueller 2010) or that seed caching often occurs near or under whitebark pine canopies (Hutchins and Lanner 1982). However, most prior studies of whitebark pine regeneration were conducted at sites that were purposively selected based on the abundance of mature whitebark pine trees, whereas our analysis was based on a probabilistic sample of 7,018 forest plots, 1,217 of which were found to have a whitebark pine component. Thus, these results represent the full range of conditions in which whitebark pine occurs throughout a large part of its range in the US Rocky Mountains. This sample is unique because probabilistic sampling is typically not used for such studies due to budgetary and logistic constraints. While purposive samples and site-specific experiments provide useful detail about ecosystem processes that affect germination, recruitment, and survival, models derived from probabilistic samples across broad scales may perform better in a wider range of environments (Edwards et al. 2006), including mixed-species stands or non-whitebark pine forest types where whitebark pine is present but is not the dominant species.

The second objective of this study was to use statistical models to characterize sites with whitebark pine seedling presence to help managers identify sites where whitebark pine seedlings are likely to occur (or not occur) in mixed-species stands. Although the three models did not distinguish identical groups of variables as important predictors, identification of the same variable by multiple models (or none of the models) provides strong evidence of that variable's importance (or lack thereof). Thus, an important result is not only identification of important variables but also of unimportant variables. The fact that forest type was not an important predictor of whitebark pine seedling presence in any of the models reinforces the conclusion that stands in the whitebark pine forest type are not necessarily the best sites for natural regeneration, and that, in fact, seedling prevalence is higher in non-whitebark pine forest types than in the whitebark pine forest type (Objective 1). This result contrasts with previous findings that whitebark pine regeneration is higher in the whitebark pine forest type and negatively related to subalpine fir importance (Larson and Kipfmueller 2010). This discrepancy may be explained by differences in sampling design: the previous results are based on purposive sampling of sites where whitebark pine was either the dominant or codominant tree species (Larson and Kipfmueller 2010), whereas our study is based on a probabilistic sampling design across all stands where whitebark pine occurs, including those dominated by species other than whitebark pine. Additionally, several metrics of overall stand density of all species were included in the models (e.g., live and dead basal area of all species, trees per acre, percent canopy cover), yet none of them emerged as important variables except as contributors to PCs.

Given the life history of whitebark pine as a high-elevation, subalpine species that tends to occupy cold sites beyond the ecological niches of most other tree species, we expected equivalent elevation and temperature to be important predictors of seedling presence. Two models directly corroborated equivalent elevation as an important predictor of whitebark pine seedling presence, random forests identified seasonal temperatures, and the logistic regression model indirectly identified elevation and temperature as represented within principal components. Similar relationships have been found in other studies (Larson and Kipfmueller 2010, Chang et al. 2014). However, random forests indicated that seasonal temperature maxima were generally more important than seasonal minima, which confirms that heat stress may affect not 
only mature tree mortality (Millar et al. 2012, Buotte et al. 2016) but also germination and growth rates of whitebark pine seedlings (McLane and Aitken 2012). Seasonal precipitation was not identified as important in any of the models except as autumn, winter, and spring precipitation related to PC2 in logistic regression. This strengthens the findings of Maloney (2014), who found temperature to be more strongly related than precipitation to whitebark pine seedling density.

All models predicted that whitebark pine seedlings are more likely to occur with increasing live whitebark pine basal area, and two of the models indicated that higher levels of dead whitebark pine basal area are also important. The importance of dead whitebark pine basal area for predicting seedling presence may reflect a positive impact of disturbance by opening canopy gaps in relatively dense stands. Meyer et al. (2016), for example, found a pulse of whitebark pine regeneration following a mountain pine beetle epidemic in the Sierra Nevada. Larson and Kipfmueller (2010) also found a positive relationship between natural regeneration and overstory mortality due to mountain pine beetle. However, not all disturbances appear to affect whitebark pine regeneration equally. In contrast to patterns observed following beetle-caused mortality, Leirfallom et al. (2015) observed a negative effect of fire severity on whitebark pine regeneration: they found fewer seedlings established at sites with high mortality or live-tree damage to mature whitebark pines than at sites with less mortality or live-tree damage. Thus, whitebark pine regeneration occurred after fire but was less abundant at sites that experienced higher severity fire (Lierfallom et al. 2015). The difference between post-fire versus post-mountain pine beetle regeneration may be explained by the differential effects of these disturbances on understory vegetation and soil. For example, mountain pine beetle epidemics do not directly disturb the understory or soil surface, nor do they always affect all species in mixed-species stands, whereas fires may affect all species in the overstory as well as understory vegetation and soil. Although disturbance was not identified as an important predictor of whitebark pine seedling presence, one model recognized reserved status, and the lower prevalence of whitebark pine seedlings within reserved areas such as national parks and wilderness areas is likely associated with the higher incidence of disturbance-related mortality (Menlove et al. 2012).

Regardless of modeling approach, percent cover of $V$. scoparium was consistently found to be positively related to whitebark pine seedling presence. Although Forcella and Weaver (1977) described the $P$. albicaulis- $V$. scoparium habitat type as having relatively low whitebark pine regeneration, other studies have found not only an association between natural regeneration of whitebark pine and V. scoparium (Pfister et al. 1977, Tomback et al. 1993, Perkins 2015) but also faster growth and higher leaf phosphorous of whitebark pine seeds planted near V. scoparium (Perkins 2015). The association of whitebark pine seedlings with $V$. scoparium may be due to any, or a combination, of the following factors: shared site preferences for the two species; a facilitative mycorrhizal association between whitebark pine and V. scoparium (Mohatt et al. 2008, Perkins 2015); or abundant caching of whitebark pine seeds in these areas by Clark's nutcrackers.

Characteristics of seedling presence sites represent both cachesite selection preferences of Clark's nutcrackers, which constrain the distribution of whitebark pine via seed dispersal (Keane et al. 2012), and conditions conducive to whitebark pine germination and seedling growth. The high whitebark pine seedling densities in the lodgepole pine forest type (Figure 2) and the fact that 35\% of all sites with whitebark pine seedlings present occurred within this type demonstrate that the lodgepole pine forest type meets the requirements of both Clark's nutcrackers (for caching) and whitebark pine (for seed germination and seedling growth). Although Lorenz et al. (2011) observed caching of whitebark pine seeds in the Douglas-fir forest type, which provides an alternate food source for the birds in years of low whitebark pine cone crops (Schaming 2016), the Douglas-fir forest type does not appear to favor whitebark pine establishment as evidenced by low seedling density (Figure 3a) and only $6 \%$ of all seedling presence sites. Although some studies have suggested that Clark's nutcrackers preferentially cache whitebark pine seeds in open patches following fire, avalanches, or other disturbances (Hansen et al. 2016), our results are more consistent with studies that reported more diverse cache-site selection ranging from mid-elevation, dense forests (Schaming 2016) to nonforest sites above treeline (Hutchins and Lanner 1982, Lorenz et al. 2011, Keane et al. 2012). This widespread seed dispersal by Clark's nutcrackers may lend adaptability to whitebark pine as the spatial distribution of its bioclimatic envelope shifts in response to changing climate (Keane et al. 2012). However, Clark's nutcrackers are known to abandon home ranges when cone crops fall below critical cone density thresholds (McKinney and Tomback 2007, McKinney et al. 2009, Keane et al. 2012) and refrain from breeding in years of low cone production (Schaming 2015). Continued mortality and low recruitment of cone-bearing whitebark pine trees could result in a smaller population of dispersers for an already declining whitebark pine population.

One caveat of this study is that seedlings observed at FIA plots may yet succumb to white pine blister rust (WPBR; Field et al. 2012). Individuals counted as seedlings may be many years or even decades old given whitebark pine's extremely slow growth rate (Tomback et al. 1993, Leirfallom et al. 2015). Thus, seedling presence alone is insufficient to indicate likelihood of recruitment into sapling and larger size classes. In addition, our study did not account for the effects of WPBR on cone production and seed dispersal, both of which are known to decrease following WPBR infection (McKinney and Tomback 2007). Although FIA distinguishes causal agents_-including diseases such as WPBR_of damage on live trees and recent mortality trees, that is, those that died within the previous 10 years (USDA 2013), WPBR might not be observed except when fruiting bodies are present, which would lead to underestimation of WPBR prevalence and failure to link WPBR with seedling absence in our models. The implication of excluding WPBR presence from our analysis is that our models of whitebark pine seedling presence do not reflect the large detrimental effect of WPBR infection on whitebark pine regeneration (McKinney and Tomback 2007, Field et al. 2012, Hansen et al. 2016, Tomback et al. 2016). This relationship is almost certainly important at spatial scales larger than FIA plots and at temporal scales longer than the 10 years included in this study, given that seedlings observed at FIA plots may have been dispersed by Clark's nutcrackers from seed sources several kilometers away (Hutchins and Lanner 1982, Lorenz et al. 2011) and that WPBR has been present in the region for multiple decades (Smith et al. 2008, Hansen et al. 2016). Had we been able to reliably include WPBR presence as a predictor of whitebark pine seedling presence, we expect there would have been a negative effect, despite the possibility that (1) infected sites may support establishment of seedlings whose seeds were dispersed from 
trees with some resistance to WPBR, and (2) WPBR may infect such seedlings in the future.

The relatively low values of TSS (Table 3) for all three of our models suggest that the models failed to include some important predictors of seedling presence, including long-term disturbance history and WPBR presence. Previous studies concluded that whitebark pine regeneration may reflect long-term disturbance histories (Tomback et al. 1993, Leirfallom et al. 2015, Perkins 2015), which are difficult to accurately quantify due to the absence of plot data and remote sensing-based evidence of past disturbance type, extent, and severity. However, the variables identified as important for natural regeneration (whitebark pine basal area, $V$. scoparium, elevation, and temperature) are likely to be consistent over the scale of several years if not decades.

Our results suggest that active management of whitebark pine should target forest types other than whitebark pine for actions such as crop tree release (Miller et al. 2007), planting of seedlings propagated from WPBR-resistant parent trees, or a combination of these actions at sites that meet the criteria described here. Crop tree release is a silvicultural treatment that identifies desirable target trees and then removes surrounding trees, typically of other species, to reduce competition for light (Nyland 2002, Miller et al. 2007). In the context of whitebark pine management, crop tree release also seeks to reduce fuel loads and has been referred to as "daylighting" (Keane et al. 2012, p. 74), although there is limited research regarding the treatment's effectiveness (Keane et al. 2012). The results of our classification model, which quantify critical threshold values of important predictors (Figure 4), imply that crop tree release and planting treatments can be most effective at sites that possess the following criteria: at least one live whitebark pine $\geq 6$ inches D.B.H. (based on the threshold for live whitebark pine basal area in Figure 4), and at least $2.4 \%$ cover of $V$. scoparium. If the second criterion is not met, the classification model indicates that sites with $\geq 84$ lodgepole pine seedlings/acre also are likely to support whitebark pine seedlings, although there is likely a maximum density of lodgepole pine seedlings at which whitebark pine seedlings can survive. However, even the highest densities of lodgepole pine seedlings in our dataset (13,194 lodgepole pine seedlings/acre) occurred on plots with multiple whitebark pine seedlings present. The failure of our seedling presence models to discriminate among forest types, combined with the results of our assessment of overall whitebark pine seedling density and distribution by forest type (Figure 3a), demonstrate that other forest types can support whitebark pine regeneration. The high proportion of sites with whitebark pine seedlings in the lodgepole pine forest type (35\%), and less so in the subalpine fir (20\%) and Engelmann spruce/subalpine fir $(23 \%)$ forest types, indicates that sites within these forest types that include a whitebark pine component should be considered as potential targets for silvicultural prescriptions targeting recruitment of whitebark pine.

Future monitoring should investigate whether whitebark pine seedlings under relatively dense canopies exhibit competitive release following disturbance, including silvicultural treatments that reduce basal area and natural disturbances such as the recent mountain pine beetle epidemic. Whitebark pine saplings and small trees up to 150 to 200 years old have demonstrated competitive release due to disturbance-induced canopy gaps (Campbell and Antos 2003), which indicates that whitebark pine responds favorably to canopy removal. Given the extensive distribution of sites with whitebark pine regeneration outside the whitebark pine forest type, projects that seek to capitalize on natural regeneration of whitebark pine may be well served by expanding their scope to include stands dominated by species other than whitebark pine.

\section{Literature Cited}

Allouche, O., A. Tsoar, and R. Kadmon. 2006. Assessing the accuracy of species distribution models: Prevalence, kappa, and the true skill statistic (TSS). J. Applied Ecol. 43(6):1223-1232.

Bechtold, W.A., and P.L. Patterson (eds.). 2005. The Enhanced Forest Inventory and Analysis Program - National Sampling Design and Estimation Procedures. Gen. Tech. Rep. FS-SRS-80. USDA Forest Service Southern Research Station, Asheville, NC. 85 p.

Breiman, L. 2001. Random forests. Mach. Learn. 45:5-32.

Breiman, L., J.H. Friedman, R.A. Olshen, and C.J. Stone. 1984. Classification and Regression Trees. Chapman and Hall, New York.

Buotte, P.C., J.A. Hicke, H.K. Preisler, J.T. Abatzoglou, K.F. Raffa, AND J.A. Logan. 2016. Climate influences on whitebark pine mortality from mountain pine beetle in the Greater Yellowstone Ecosystem. Ecol. Appl. 26(8):2507-2524.

Campbell, E.M., and J.A. Antos. 2003. Postfire succession in Pinus albicualis - Abies lasiocarpa forests of southern British Columbia. Can. J. Botany. 81:383-397.

Chang, T., A.J. Hanse, and N. Piekielek. 2014. Patterns and variability of projected bioclimatic habitat for Pinus albicaulis in the Greater Yellowstone Area. PLoS ONE. 9(11):e111669.

Cleland, D.T., J.A. Freeouf, J.E. Keys, JR, G.J. Nowacki, C. Carpenter, W.H. McNAB. 2007. Ecological Subregions: Sections and Subsections for the Conterminous United States. Gen. Tech. Rep. GTR-WO-76. USDA Forest Service, Washington, DC.

Cutler, D.R., T.C. Edwards, K.H. Beard, et Al. 2007. Random forests for classification in ecology. Ecology. 88:2783-2792.

Daly, C., R.P. Neilson, and D.L. Phillips. 1994. A statistical-topographic model for mapping climatological precipitation over mountainous terrain. J. Appl. Meteor. 33:140-158.

Edwards, T.C., Jr, D.R. Cutler, N.E. Zimmermann, L. Geiser, and G.G. Moisen. 2006. Effects of sample survey design on the accuracy of classification tree models in species distributions models. Ecol. Modell. 199:132-141.

Field, S.G., A.W. Schoettle, J.G. Klutsch, S.J. Tavener, And M.F. Antolin. 2012. Demographic projection of high-elevation white pines infected with white pine blister rust: A nonlinear disease model. Ecol. Appl. 22:166-183.

Forcella, F., and T. Weaver. 1977. Biomass and productivity of the subalpine Pinus albicaulis-Vaccinium scoparium association in Montana, USA. Vegetatio. 35(2):95-105.

Goeking, S., AND D.K. IzLAR. 2014. Natural regeneration of whitebark pine: Factors affecting seedling density. Int. Forestry Rev. 16(5):133.

Goeking, S.A., and D.K. Izlar. 2018. Pinus albicaulis Engelm. (whitebark pine) in mixed-species stands throughout its US range: Broadscale indicators of extent and recent decline. Forests. 9:131.

Hansen, A., K. Ireland, K. Legg, et al. 2016. Complex challenges of maintaining whitebark pine in Greater Yellowstone under climate change: A call for innovative research, management, and policy approaches. Forests. 7(3):54.

Hastie, T., Tibshirani, R., and Friedman, J. 2016. The Elements of Statistical Learning, 2nd ed. Springer, New York. 745 p.

Hutchins, H.E., And R.M. Lanner. 1982. The central role of Clark's nutcracker in the dispersal and establishment of Whitebark pine. Oecologia. 55:192-201. 
James, G., D. Witten, T. Hastie, and R. Tibshirani. 2013. An Introduction to Statistical Learning. Springer, New York. 426 p.

Keane, R.E., and S.F. Arno. 1993. Rapid decline of whitebark pine in western Montana: Evidence from 20-year remeasurements. West. J. Appl. For. 8(2):44-47.

Keane, R.E., and R.A. Parsons. 2010. Restoring whitebark pine forests of the northern Rocky Mountains, USA. Ecol. Rest. 28(1):56-70.

Keane, R.E., D.F. Tomback, C.A. Aubry, et al. 2012. A Range-Wide Restoration Strategy for Whitebark Pine (Pinus albicaulis). Gen. Tech. Rep. RMRS-GTR-279. USDA Forest Service Rocky Mountain Research Station, Fort Collins, CO. 108 p.

Kunn, M., And K. Johnson. 2016. Applied Predictive Modeling. Springer, New York. 600 p.

Larson, E.R., and K.F. Kipfmueller. 2010. Patterns in whitebark pine regeneration and their relationships to biophysical site characteristics in southwest Montana, central Idaho, and Oregon, USA. Can. J. of Forest Res. 40:476-487.

Leirfallom, S.B., R.E. Keane, D.F. Tomback, and S.Z. Dobrowski. 2015. The effects of seed source health on whitebark pine (Pinus albicaulis) regeneration density after wildfire. Can. J. Forest. Res. 45:1597-1606.

LiaW, A., AND M. Wiener. 2002. Classification and regression by randomForest. $R$ News. 2(3):18-22.

Little, E.L., Jr. 1971. Atlas of United States Trees, Volume 1, Conifers and Important Hardwoods: Misc. Pub. 1146. U.S. Department of Agriculture, Washington, DC. 9 p., 200 maps.

Lonergan, E.R., C.L. Cripps, and C.M. Smith. 2014. Influence of site conditions, shelter objects, and ectomycorrhizal incoluation on the early survival of whitebark pine seedlings planted in Waterton Lakes National Park. For. Sci. 60:603-612.

Lorenz, T.J., K.A. Sullivan, A.V. Bakian, and C.A. Aubry. 2011. Cache-site selection in Clark's nutrcracker (Nucifraga columbiana). Auk. 128(2):237-247.

Macfarlane, W.W., J.A. Logan, and W.R. Kern. 2013. An innovative aerial assessment of Greater Yellowstone Ecosystem mountain pine beetle-caused whitebark pine mortality. Ecol. Appl. 23:421-437.

Mahalovich, M.F., And V.D. Hipkins. 2011. Molecular genetic variation in whitebark pine (Pinus albicaulis Engelm.) in the Inland West. P. 118-132 in The Future of High-Elevation, Five-Needle White Pines in Western North America: Proceedings of the High Five Symposium, 28-30 June 2010; Missoula, MT. Keane, R.E., D.F. Tomback, M.P. Murray, C.M. Smith (eds.). Proceedings RMRS-P-63. USDA Forest Service, Rocky Mountain Research Station, Fort Collins, CO.

Maloney, P.E. 2014. The multivariate underpinnings of recruitment for three Pinus species in montane forests of the Sierra Nevada, USA. Plant Ecol. 215:261-274.

McCaughey, W.W., G.L. Scott, and D.K. Izlar. 2009. Whitebark pine planting guidelines. West. J. Appl. For. 24(3):163-166.

McCune, B., And D. Keon. 2002. Equations for potential annual direct incident radiation and heat load. J. Veg. Sci. 13:603-606.

McKinney, S.T., C.E. Fielder, And D.F. Tomback. 2009. Invasive pathogen threatens bird-pine mutualism: Implications for sustaining a highelevation ecosystem. Ecol. Appl. 19:597-607.

McKinney, S.T., and D.F. Tomback. 2007. The influence of white pine blister rust on seed dispersal in whitebark pine. Can. J. Forest Res. 37(6):1044-1057.

McLane, S.C., And S.N. Aitken. 2012. Whitebark pine (Pinus albicaulis) assisted migration potential: Testing establishment north of the species range. Ecol. Appl. 22:142-153.

Menlove, J., Shaw, J.D., Thompson, M.T., Witt, C., Amacher, M.C., Morgan, T.A., Sorenson, C., McIver, C., Werstak, C. 2012. Montana's forest resources, 2003-2009. Resour. Bull. RMRS-RB-15. USDA Forest Service, Rocky Mountain Research Station, Fort Collins, CO. 140 p.
Meyer, M.D., B. Bulaon, M. MacKenzie, and H.D. Safford. 2016. Mortality, structure, and regeneration in whitebark pine stands impacts by mountain pine beetle in the Sierra Nevada. Can. J. Forest Res. 46:572-581.

Miles, P.D. 2017. Forest Inventory EVALIDator Web-Application Version 1.6.0.03. USDA Forest Service, Northern Research Station, St. Paul, MN. Available online: http://apps.fs.fed.us/Evalidator/evalidator.jsp; last accessed March 30, 2017.

Millar, C.I., R.D. Westfall, D.L. Delany, M.J. Bokach, A.L. Flint, AND L.E. FLINT. 2012. Forest mortality in high-elevation whitebark pine (Pinus albicaulis) forests of eastern California, USA: Influence of environmental context, bark beetles, climatic water deficit, and warming. Can. J. Forest Res. 42:749-765.

Miller, G.W., J.W. Stringer, and D.C. Mercker. 2007. Technical Guide to Crop Tree Release in Hardwood Forests. University of Tennessee Extension, Knoxville, TN. 24 p.

Mohatt, K.R., C.L. Cripps, and M. Lavin. 2008. Ectomycorrhizal fungi of whitebark pine (a tree in peril) revealed by sporocarps and molecular analysis of mycorrhizae from treeline forests in the Greater Yellowstone Ecosystem. Botany. 86:14-25.

Nyland, R.D. 2002. Silviculture: Concepts and Applications. Waveland Press Inc, Long Grove, IL. 682 p.

O'Connell, B.M., B.L. Conkling, A.M. Wilson, et Al. 2016. The Forest Inventory and Analysis Database: Database Description and User Guide Version 6.1.1 for Phase 2. USDA Forest Service, Washington, DC. 870 p. Available online: http://www.fia.fs.fed.us/library/database-documentation/current/ver611/FIADB\%20User\%20Guide\%20P2_6-1-1_final. pdf; last accessed March 30, 2017.

Perkins, J.L. 2015. Fire enhances whitebark pine seedling establishment, survival, and growth. Fire Ecol. 11:84-99.

Pfister, R.D., B.L. Kovalchik, S.F. Arno, and R.C. Presby. 1977. Forest Habitat Types of Montana. Gen. Tech. Rep. INT-GTR-34. USDA Forest Service, Intermountain Forest and Range Experiment Station, Ogden, UT. 174 p.

PRISM Climate Group. 2012. Oregon State University. Created 1 July 2012. Available online: http://prism.oregonstate.edu; last accessed June 1, 2017.

R Core Team. 2016. R: A Language and Environment for Statistical Computing. R Foundation for Statistical Computing, Vienna, Austria. Available online: https://www.R-project.org/; last accessed March 30, 2017.

Raffa, K.F., B.H. Aukema, B.J. Bentz, et AL. 2008. Cross-scale drivers of natural disturbances prone to anthropogenic amplification: The dynamics of bark beetle eruptions. Bioscience. 58(6):501-517.

Retzlaff, M.L., S.B. Leirfallom, and R.E. Keane. 2016. A 20-Year Reassessment of the Health and Status of Whitebark Pine Forests in the Bob Marshall Wilderness Complex, Montana. Res. Note RMRS-RN-73. USDA Forest Service, Rocky Mountain Research Station, Fort Collins, CO. 10 p.

Rivas-Martínez, S., D. Sánchez-Mata, and M. Costa. 1999. North American boreal and western temperate forest vegetation. Itinera Geobot. 12:5-316.

Schaming, T.D. 2015. Population-wide failure to breed in the Clark's nutcracker (Nucifraga columbiana). PLoS One. 10(5):e0123917. DOI: 10.1371/journal.pone.0123917.

Schaming, T.D. 2016. Clark's nutcracker breeding season space use and foraging behavior. PLoS One. 11(2):e0149116. DOI: 10.1371/journal. pone.0149116.

Schoettle, A.W. and R.A. Sniezko. 2007. Proactive intervention to sustain high elevation pine ecosystems threatened by white pine blister rust. J. Forest Res. 12:327-336.

Smith, C.M., B. Wilson, S. Rasheed, R.C. Walker, T. Carolin, and B. SHEPHERD. 2008. Whitebark pine and white pine blister rust in the Rocky Mountains of Canada and northern Montana. Can. J. Forest Res. 38:982-995.

Therneau, T., B. Atkinson, and B. Ripley. 2015. rpart: Recursive Partitioning and Regression Trees. R package version 4.1-10. Available 
online: https://CRAN.R-project.org/package=rpart; last accessed March 30, 2017.

Tomback, D.F., L.M. Resler, R.E. Keane, E.R. Pansing, A.J. Andrade, and A.C. Wagner. 2016. Community structure, biodiversity, and ecosystem services in treeline whitebark pine communities: Potential impacts from a non-native pathogen. Forests. 7(1):21.

Tomback, D.F., S.K. Sund, and L.A. Hoffman. 1993. Postfire regeneration of Pinus albicaulis: Height-age relationships, age structure, and microsite characteristics. Can. J. Forest Res. 23:113-119.

USDA Forest Service. 2013. Interior West Forest Inventory and Analysis Forest Survey field procedures, Ver. 5.0. Available online: http://www. fs.fed.us/rm/ogden/data-collection/pdf/iwfia_p2_60.pdf; last accessed March 30, 2017.

US Fish and Wildlife Service. 2011. Endangered and threatened wildlife and plants: 12-month finding on a petition to list Pinus albicaulis as endangered or threatened with critical habitat. Fed. Regist. 76(138):42631-42654.

Windmuller-Campione, M.A., and J.N. Long. 2016. Limber pine (Pinus flexilis James), a flexible generalist of forest communities in the intermountain west. PLoS ONE. 11(8):e0160324.

Zar, J.H. 1996. Biostatistical Analysis, 3rd ed. Prentice Hall, Upper Saddle River, NJ. 662 p., plus appendices. 